\title{
GÊNESE DO MOVIMENTO ESTUDANTIL NA ESCOLA DE ENFERMAGEM DA UNIVERSIDADE FEDERAL DA BAHIA (1947-1959)
}

\author{
Genesis of student organization in the Nursing School of University \\ Federal of Bahia, Brazil (1947-1959)
}

Genesis del movimiento estudantil en la Escuela de Enfermeria, Universidad Federal de Bahia (1947-1959)

Cidia Daniela de Oliveira Pires ${ }^{1}$

Cristina Maria Meira de Melo²

\section{RESUMO}

Estudo histórico-social da gênese do movimento estudantil na Escola de Enfermagem da Universidade Federal da Bahia no período de 1947 a 1959. Os objetivos do estudo são: descrever o contexto sócio-político da época estudada; descrever a emergência do movimento estudantil quando da fundação do Diretório Acadêmico; identificar o perfil das militantes e analisar a participação destas nas lutas estudantis. Os dados foram coletados por meio das Atas do Diretório Acadêmico, da consulta aos periódicos da época e das entrevistas realizadas através da História Oral. As narrativas evidenciam que o Diretório Acadêmico compartilhava dos mesmos propósitos da direção da Escola de Enfermagem, legitimando as regras por ela impostas e divulgando para a sociedade baiana o novo curso, no sentido de desconstruir os preconceitos e representações inerentes ao surgimento da profissão. Todavia, em outras escolas da Universidade e no Brasil, lutava-se por mais autonomia do País e em defesa do ensino público.

Plavras-chave: História. Movimento Estudantil. Enfermagem.

\begin{abstract}
The study focus the genesis of the student organization at a Nursing School since 1947 until 1959. The objectives are: to describe the social and political context; to describe the emergency of student's fights; to identify the profile of the participants of the political organization and to analyze the participation of the students in those fights. The data were collected from the documents of the Nursing Directory, newspapers and interviews done with oral history technique. The information collected revels that the Nursing Directory shares the same proposals of the Nursing School direction, who was interested in the divulgation of the new course. In the other hand, students organizations at the same University and in others regions of Brazil fight by public schools and the political autonomy of the Country.
\end{abstract}

\section{Resumen}

Es un estudio histórico social cuyo objeto de investigación es la génesis del Directorio Estudiantil en una Escuela de Enfermería de 1947-1954, con objetivos de: describir el contexto sociopolítico; describir la emergencia del movimiento estudiantil; identificar el perfil de las militantes y analizar la participación de estas en las luchas estudiantiles. Los dados fueran colectados en las actas del Directorio, consulta en los periódicos publicados en el período y en las entrevistas con la técnica de Historia Oral. Las narrativas evidencian que la entidad estudiantil compartía de los mismos propósitos de la dirección de la Escuela y haciendo la difusíon en la sociedad local el nuevo curso. Todavía, en otras unidades de la Universidad y en el Brasil las luchas de los estudiantes eran por la autonomía del País y en defensa de la enseñanza pública. En contrapartida, la actuación de las participantes del Directorio estaba limitada a los intereses de la dirección. 


\section{INTRODUÇÃO}

Na universidade, os Centros e Diretórios Acadêmicos se constituem como espaços legitimados para o primeiro contato do estudante com o movimento estudantil. A vivência neste ambiente, fora da sala de aula, propicia a identificação e 0 entendimento de fatores e problemas do contexto social, permitindo ao estudante conhecer sua realidade. Além disso, amplia-se a compreensão do papel e da prática na futura profissão.

0 Diretório Acadêmico da EEUFBA surgiu após um ano da criação do primeiro curso de Enfermagem da Bahia e terceiro do Brasil, em 1947. No mesmo ano foi criada a Universidade da Bahia, atualmente Universidade Federal da Bahia (UFBA), no bojo de uma série de mudanças na sociedade brasileira, advindas do processo de industrialização iniciada no governo do presidente Eurico Gaspar Dutra.

Na época da criação da UFBA, a inserção feminina no ensino superior era bastante reduzida. As mulheres que tinham acesso ao estudo superior provinham, em sua maioria, das camadas mais ricas da sociedade baiana.

Se no começo havia menos politização das estudantes da EEUFBA, isso se explica, entre outros motivos, pela estreita relação de poder entre a Escola de Enfermagem e o reitorado da época, pois esse foi um projeto considerado pessoal do reitor Edgar Santos. Além disso, era patente o reduzido poder político feminino no contexto da sociedade da época.

A partir dessa compreensão é que se toma como objeto de estudo a gênese do movimento estudantil da Escola de Enfermagem da Universidade Federal da Bahia (1947-1959). Esse período compreende 0 ano de criação do Diretório Acadêmico e sua primeira década de atuação; este é o primeiro estudo sobre o tema.

Este estudo se justifica pelas indagações dos participantes do Diretório Acadêmico (DA) da EEUFBA na busca de informações sobre a origem do movimento estudantil em Enfermagem. 0 interesse em desenvolvê-lo foi influenciado também por outras entidades estudantis, preocupadas em pesquisar e documentar a história do movimento estudantil no âmbito universitário. Este tema justifica-se fundamentalmente no fato de que o estudo da história nos possibilita compreender as pessoas no seu tempo, e as mudanças contínuas no tempo, para aprender a agir no tempo de agora.

Para nortear o estudo foi formulada a seguinte questão: Como ocorreu o movimento estudantil da Escola de Enfermagem da Universidade Federal da Bahia, da fundação do Diretório Acadêmico ao final da década de 1950? Os objetivos são: descrever o contexto sócio-político da época; descrever a emergência do movimento estudantil da EEUFBA quando da fundação do Diretório Acadêmico e durante seus anos iniciais; identificar o perfil das militantes do movimento estudantil e analisar a participação das mesmas nas lutas estudantis.

\section{METODOLOGIA}

Esta é uma pesquisa histórico-social com abordagem qualitativa. A coleta de dados foi realizada através da técnica de história oral e documental. A investigação utilizando a história oral consiste na produção de documentos históricos. 0 conjunto dos depoimentos, do contexto e das ideologias permite elucidar a validade dos fatos e revelar o todo de um projeto de pesquisa ${ }^{1}$.

As entrevistadas foram selecionadas dentre aquelas que eram engajadas no movimento estudantil da EEUFBA no período entre 1947 e 1959 e que aceitaram ser participantes do estudo, somando um total de cinco entrevistas.

A realização das entrevistas ocorreu em duas etapas. Inicialmente foi construído o roteiro individual com a finalidade de levantar desde informações pertinentes à identificação da entrevistada até 0 seu ingresso na EEUFBA. A segunda etapa caracterizou-se pelo desenvolvimento do roteiro geral, constando da participação da entrevistada no DA e a busca de informações a partir da cronologia dos fatos registrados nas atas no período compreendido por este estudo. Com isso, buscase a comparação entre as entrevistas e a identificação de "divergências, recorrências, ou ainda concordâncias entre as diferentes versões obtidas ao longo da pesquisa, aprofundandose as possibilidades de análise do acervo" ?

A coleta de dados se fez nos meses de setembro a novembro de 2007 mediante a assinatura dos participantes do Termo de Consentimento Livre e Pré-Esclarecido.

As atas estudadas somam 138 sessões. A leitura das atas foi integral, com foco para a estrutura do DA; as atividades prioritárias; a relação estabelecida com a diretoria da Escola e as demais estudantes; e participação das estudantes de Enfermagem nas reuniões do DA, no movimento estudantil geral, nos congressos estudantis, na União dos Estudantes da Bahia (UEB) e no Diretório Central dos Estudantes (DCE).

Para análise dos dados utilizou-se a narrativa. Esta técnica possibilita a compreensão dos fatos, permite contar um episódio de forma seqüencial, utilizando-se do enredo, das personagens, do tempo, do espaço e do ambiente relacionados com o objeto do estudo ${ }^{3}$.

\section{O CONTEXTO SÓCIO-POLÍTICO DO BRASIL}

Após a derrubada do Estado Novo (1937-1945) - regime ditatorial sob o comando de Getúlio Vargas - assumiu provisoriamente a presidência da República João Linhares. Para o período de 1946 a 1951 foi eleito presidente o Marechal Eurico Gaspar Dutra, ex-ministro da Guerra no supracitado regime.

o Governo Dutra foi caracterizado por uma política econômica liberal, principalmente quanto à importação de bens, e pelo arrocho salarial. Ele acreditava que o controle estatal era nocivo para o desenvolvimento do País. Na prática, esse modelo fracassou, o que fez o governo mudar de política e estabelecer critérios para a importação de bens e produtos. Em conseqüência, houve um estímulo à produção para 0 mercado interno, favorecendo o crescimento da indústria nacional4. 
No âmbito externo, tinha início a Guerra Fria - confronto político, militar, econômico e ideológico entre os Estados Unidos da América (EUA) e a União das Repúblicas Socialistas Soviéticas (URSS) e os seus respectivos aliados, como conseqüência da II Grande Guerra ${ }^{5}$. 0 governo brasileiro assumiu posição ao lado dos EUA e rompeu com a URSS, estreitando cada vez mais os laços políticos e econômicos com seu aliado, o que predominou nos anos seguintes ${ }^{4}$.

Dutra foi sucedido por Getúlio Vargas, que voltou a ocupar a presidência da República, governando sob o regime democrático, após ser eleito pelo povo. 0 mandato de Vargas foi caracterizado por várias medidas nacionalistas: 0 controle da remessa de lucros para o exterior, prosseguimento ao projeto de indústria nacional, elevação do salário mínimo de $100 \%$, além da criação da Petrobrás4.

Getúlio prosseguiu no seu mandato presidencial assumindo uma política nacionalista e populista, desencadeando uma insatisfação generalizada entre os conservadores. As fortes pressões de seus opositores levaram-no ao suicídio e ao fim da era Vargas, em 19544.

Em 1955 foram realizadas as eleições presidenciais, com as vitórias de Juscelino Kubitschek para presidente e João Goulart para vice. Ao contrário da política nacionalista de Getúlio, Juscelino procurou atingir o desenvolvimento nacional de outra maneira. Para isso, o País precisava viabilizar uma política econômica combinando ações do próprio Estado, da empresa nacional privada e do capital estrangeiro, com ênfase na industrializaçãa ${ }^{4}$.

Como parte da política econômica, Juscelino estabeleceu um Programa de Metas, priorizando os seguintes setores: energia, transporte, alimentação, indústria de base, educação e a construção de Brasília. Os resultados desse programa contagiaram de otimismo os brasileiros, porém esse clima não durou muito. Logo depois veio o aumento da inflação, como conseqüência dos gastos com a construção de Brasília e com os aumentos salariais do funcionalismo, além do crédito fácil concedido ao setor privado, dentre outros fatores ${ }^{4}$.

No entanto, na memória dos brasileiros, o governo Juscelino é lembrado como um período de otimismo e grandes realizações, dentre elas a construção de Brasília ${ }^{4}$.

No campo da saúde, nos primeiros anos do século XX houve um aumento crescente das chamadas doenças de massa. 0 aparecimento dessas doenças estava relacionado às condições de vida e trabalho da população. A melhoria desse quadro se tornava fator condicionante para o controle daquelas patologias ${ }^{6}$.

Assim, uma série de campanhas foi desenvolvida tendo como finalidade a eliminação das doenças de massa. Para 0 Brasil, a necessidade do controle dessas doenças foi determinante para a criação dos cursos de Enfermagem profissional a partir de $1923^{6}$. Na Bahia, a necessidade de apoio ao Hospital das Clínicas foi o elemento impulsionador da criação da EEUFBA; relatos de professoras de gerações anteriores indicam que o reitor Edgard Santos considerava que o hospital, para ser moderno, deveria ter um serviço de enfermagem organizado e com a mesma posição hierárquica do serviço médico.
0 quadro de modernização implementado nacionalmente, revelava que a criação dos cursos de Enfermagem esteve sempre atrelada às exigências do contexto sócio-econômico brasileiro, modificando por sua vez o perfil do profissional em Enfermagem?. Se antes não se exigia qualificação para as mulheres que desempenhavam o serviço de cuidado aos doentes, passa-se a uma cobrança de maior escolaridade e competência, regulando a atividade leiga para tornar-se uma nova profissão. Para isso as escolas buscavam atrair estudantes das camadas sociais e econômicas privilegiadas, pensando transportar para a nova profissão o status social e refinamento pessoal das alunas.

\section{0 movimento nacional dos estudantes e a participação das estudantes de Enfermagem}

Anterior à criação da União Nacional dos Estudantes (UNE), a entidade representativa dos estudantes era denominada Casa dos Estudantes do Brasil (CEB), um órgão paraoficial e que se isentava das discussões políticas.

A superação dessa realidade ocorre em 1937, após a realização do I Conselho Nacional de Estudantes, que votou um regimento e elegeu uma nova diretoria.

Em 1947, a UNE lança uma campanha em defesa do patrimônio territorial e econômico, com foco no monopólio estatal do petróleo e na luta pela criação da Petrobrás, intitulada "O Petróleo é Nosso" 8.

No ano seguinte, dando continuidade à campanha pela nacionalização do petróleo, a entidade desenvolvia a luta contra 0 aumento das passagens do transporte coletivo no Rio de Janeiro ${ }^{8}$.

Em 1949, um dos resultados importantes da luta estudantil foi a conquista da gratuidade do ensino universitário ${ }^{9}$. Em julho de 1950 teve início uma fase direitista quando "a UNE viveu até 1956 sob o controle de forças extremamente retrógradas e a serviço do imperialismo norte-americano" $8: 21$. A UNE só foi reconquistada pelos estudantes progressistas em $1956^{9}$.

Durante o governo JK diversas vezes os estudantes demonstraram repulsa às autoridades nor te-americanas. 0 s resquícios da política nacionalista de Vargas levaram a UNE a defender a bandeira contra 0 entreguismo. 0 termo era entendido pelos estudantes e setores da esquerda como uma abertura exagerada do Brasil aos interesses dos Estados Unidos e ao capital estrangeiro ${ }^{10}$.

Em 1959, a UNE destacou-se na luta contra o projeto de Diretrizes e Bases da Educação Nacional que acabava com 0 ensino público e gratuito e promovia o crescimento das instituições privadas ${ }^{8}$.

No entanto, toda essa movimentação parecia distante e ressoava com pouco interesse na vida das estudantes da recém-criada Escola de Enfermagem da UFBA.

A Universidade da Bahia seguiu a tendência dos grandes centros no desenvolvimento da enfermagem hospitalar. Com 0 Hospital das Clínicas já em processo final de construção, 0 reitor Edgard Rêgo Santos instituiu o primeiro curso de Enfermagem. 
Em 22 de janeiro de 1946 foi criada a Escola de Enfermagem da Universidade da Bahia (denominada assim até 1965, quando se tornou Universidade Federal da Bahia), anexa à Faculdade de Medicina, condição que perdurou até $1950^{11}$.

A busca do fortalecimento e reconhecimento para implantação da profissão na Bahia pode ser notada pelo convite feito às enfermeiras formadas pela Escola Anna Nery do Rio de Janeiro e pela Escola de Enfermagem da Universidade de São Paulo (USP) para lecionar na EEUFBA ${ }^{11}$. 0 quadro docente era escolhido para dar continuidade à orientação teórica anglosaxônica de base religiosa, seguindo o modelo da Escola Anna Nery, considerada padrão para 0 ensino e formação das enfermeiras para todo 0 País ${ }^{12}$.

Havia também exigências quanto ao perfil das candidatas ao curso de Enfermagem, tais como: boas condições físicas, orientação religiosa, nível cultural, social, econômico e moral. Outros destaques estavam no interesse em ajudar o próximo, na existência de instinto maternal e na persistência e no equilíbrio demonstrado pela candidata ${ }^{12}$.

0 altruísmo e a imagem do servir eram fortemente propagandeados pela EEUFBA na divulgação do novo curso.

Eu gostava muito de matemática, de física, gostava de desenho. Então fui para 0 1ㅇano científico e comecei a estudar já pensando em fazer vestibular para Engenharia. Quando foi no último semestre do científico (já fazendo cursinho pré-vestibular), o Ginásio Americano recebeu a visita da professora Haydeé Dourado. Era uma palestra de recrutamento de jovens para fazer enfermagem. Mostrou como as enfermeiras ajudavam as pessoas, as visitas domiciliares, o trabalho da horta, 0 ato de servir, eu fiquei encantada. Ela mostrava como era o cuidado exercido pelas enfermeiras, e eu nunca tinha visto aquilo. Tinha dezessete anos e quando ela terminou, eu disse: é isso que eu quero fazer, é essa profissão que eu quero. (E 2)

Em 1948, a Escola ganha um prédio próprio, onde ainda funciona atualmente. Além de oferecer ensino às estudantes, 0 prédio constituiu-se em espaço de residência - deter minação legal para todas as escolas de Enfermagem brasileiras - e lazer para as internas e suas professoras, proporcionando 0 convívio entre ambas ${ }^{11}$.

A Escola zelava pela moral de suas alunas e docentes, de modo que a vida pessoal de ambas era fiscalizada. Seus passos e atitudes também eram vigiados, a fim de manter 0 perfil desejado para as futuras enfermeiras. Simultaneamente, promovia a segregação das discentes com o mundo externo, tendo como objetivo impedir possíveis transgressões ${ }^{12}$.

Esse modelo de escola não favorecia a inserção no mundo e muito menos ao engajamento político das suas alunas, 0 que vai se refletir na organização e militância estudantil das alunas da EEUFBA. Essa alienação do mundo, resultante de um aparelho formador tradicional, conservador e de forte conteúdo moral, parece produzir seus frutos sobre estudantes e enfermeiras em pleno século XXI.
Os relatos e os registros das atas revelam que a participação do DA no movimento estudantil em geral tinha um caráter distinto de outros grupos de estudantes. Após a participação em congressos estudantis, a avaliação que se seguia era sempre de reprovação quanto aos acontecimentos vivenciados. Por outro lado, nos congressos de Enfermagem de caráter profissional, os comentários registrados em atas são sempre de aprovação. Os registros demonstram que os membros do DA não tinham uma identificação com os temas do movimento estudantil da época, e por fim com qualquer tema de caráter político.

Nessa época, da década de 50, os estudantes de Enfermagem não ligavam muito com problemas políticos. [...] Não despertavam interesse [...] Nesse tempo os estudantes, inclusive os de Enfermagem, não participavam da vida ativa da política nacional. Não tomavam muito conhecimento do que se estava passando no Brasil, e se tinham eram coisas que eles não alimentavam para discussão. (E 5).

A colega presidente com a palavra falou da participação no Congresso de Enfermagem no Hotel Quitandinha e no Congresso de Estudantes em Goiás. Referindo-se ao de Enfermagem, teceu elogios a nossa mui digna Diretora Nilza Garcia, e sobre o Congresso de Goiânia, a colega presidente achou que fugiu do terreno universitário para o da política. (ATA DO DA de 5.08.1953)

Também demonstravam o processo de alienação vivido, desde que as alunas admitiam fazer tudo que era solicitado por outras entidades estudantis, menos atividades relacionadas com táticas tradicionalmente utilizadas pelos estudantes para reivindicar. Essa postura reflete uma atuação condicionada a uma prévia aprovação da diretoria da Escola ao grupo dirigente do DA e ao rígido código de conduta exigido das alunas, como revela a entrevista a seguir que destaca que "nós de enfermagem resolvíamos nossos problemas entre nós".

Agora, tudo que iam (refere-se a outras entidades e dirigentes estudantis) nos pedir nós acatávamos. Mas não podíamos fazer grandes coisas, filar aula, fazer greve, não ter aula...Perdia 0 ano, não se formava, era uma confusão, era um rigor danado, colégio de freira (riso). Você não faz idéia do que era a Escola de Enfermagem no nosso tempo. A Escola era muito dura, muito cheia de regras, era uma coisa muito controlada [...]. A gente dava apoio, mas não entrava em greve [...]. Quem é que ousava. Nós de enfermagem resolvíamos nossos problemas entre nós. A gente fazia saúde pública, saúde pública rural e procurava transmitir ao povo aquilo que a gente achava e via como importante. Então, nós já estávamos preocupados e agindo no 
social pelo próprio trabalho do curso de Enfermagem. (E1)

Nas atas registra-se a participação do DA na Campanha Pró-flagelados promovida pela União dos Estudantes da Bahia (UEB).

A presidente falou que viria aqui na Escola uma comissão de estudantes da U.E.B a fim de convidarmos a cooperar na Campanha próflagelados. Todas prometeram colaboração. (ATA DO DA de 2.03.1952)

A Campanha objetivava arrecadar alimentos no comércio de Salvador para distribuir entre as vítimas da seca e a visita dos estudantes as áreas atingidas. 0 engajamento nesta Campanha revela que as alunas participavam do que foi nomeado como trabalho social e não político, portanto atividade aceitável para ser exercida por moças, até pela direção da Escola.

A UEB tinha como objetivo não só o atendimento das necessidades estudantis, como também as necessidades sócias da época, por exemplo, os flagelados. A UEB assumia a campanha dos flagelados, e a Escola já tinha uma comissão que arrecadava material para os flagelados e direcionava para a UEB [...]. A gente arrecadava comida, roupa, lençóis, abrigos para mandar para os flagelados, pessoas que ficavam sem ter onde morar, que fugiam da seca. Porque esses flagelados eram quem fugia da seca, quem não tinha onde ficar. Então essa comissão fazia isso, arrecadava material para os flagelados. (E 2)

Além dos aspectos analisados, não era simples para as mulheres, muito menos para as estudantes de Enfermagem, participar de entidades e de ações políticas. Esse não era 0 papel que a sociedade esperava das mulheres, como analisado anteriormente. E mesmo nas entidades estudantis, não existiam relações e espaço igualitário entre homens e mulheres, como narra uma das entrevistadas, reforçando a dificuldade de engajamento político das alunas de Enfermagem.

E nós mulheres não falávamos. Éramos muito poucas. Mas a gente votava. Agora na UEB, a gente se pronunciava. Na UNE não, porque mulher, sabe como é [...]. (E2)

\section{A criação do Diretório Acadêmico e o movimento estudantil da Escola de Enfermagem da UFBA}

Sobre a data de fundação do DA existem duas versões. A primeira é de uma integrante da primeira gestão do Diretório que faz referência a sua criação no mesmo dia da primeira aula na EEUFBA. A outra é proveniente do livro de atas do DA. Podese inferir que a segunda foi uma reunião formal e mais extensa, com outros assuntos a decidir, e reforça que a criação do DA foi uma iniciativa da direção da Escola.
Após a aula de D. Haydeé, no dia doze de março de 1947, ela nos orientou, porque não tínhamos experiência, aos pontos principais que as alunas iriam seguir: 1) Naquela época se fazia uma eleição para uma estudante representar a classe, se chamava representante de classe. Essa representante de classe tinha a função de manter contato com a estudante e a direção da Escola e com os professores. Através dessa representante de classe é que nós nos comunicávamos e tínhamos orientações necessárias. A representante de classe nós indicamos Juju, que era Julieta Villas-Bôas, porque ela tinha muita participação na Escola, ela já tinha ligações com a diretora e estava mais influenciada na direção da Escola que qualquer uma de nós. Depois que a escolhemos para representante de classe, nós fizemos nova reunião, nesse mesmo dia, para criar o DA; na mesma hora nós achávamos que ela seria a mais indicada, a pessoa para ser a presidente. Então foi eleita a primeira presidente do Diretório Acadêmico da Escola de Enfermagem. (E 5)

0 depoimento acima indica que a escolha da primeira presidente do DA se deu influenciada pela sua boa relação e aceitação junto à direção da Escola. Esta era quem orientava as estudantes em todas as suas ações, como bem retrata as atas, além das entrevistas. Ressalte-se em particular o fato inusitado de que a diretora presidia as reuniões do DA, como confirma a ata a seguir.

Aos dezesseis de abril de mil novecentos e quarenta e sete, realizou-se a primeira reunião da Associação de Estudantes da Escola de Enfermagem da Bahia sob a presidência da diretora da Escola, para fins de eleição da diretoria e discussão dos Estatutos. (ATA DO DA de 4.8.1947)

Esse fato indica que a relação entre a direção da Escola de Enfermagem e o Diretório Acadêmico não só era próxima como de subordinação.

$\mathrm{Na}$ análise do perfil das militantes do movimento estudantil da EEUFBA, algumas estudantes eram oriundas das escolas tradicionais de Salvador, 0 que revela também uma condição social elevada, como demonstrado a seguir.

Eu fui aluna do curso de ginásio do colégio Dona Afrísia, um colégio em Nazaré muito bom [...], freqüentado por filhos de médicos, advogados, engenheiros, funcionários públicos. Classe média e média alta. Um padrão muito alto porque Dona Afrísia Santiago tinha uma visão de educação muito avançada. (E 1).

Naquela época a EEUFBA não exigia o segundo grau completo para o ingresso no curso, mas as entrevistas revelam que essa também não era a prioridade na educação 
das moças, mesmo das camadas sociais mais altas, como revela uma das entrevistadas:

Agora eu não tinha curso de colégio porque meu pai tornou-se deputado federal e nós nos mudamos para o Rio de Janeiro. (E1)

Algumas das escolas freqüentadas anteriormente pelas futuras enfermeiras eram religiosas, o que correspondia aos interesses da EEUFBA em manter a tradição religiosa da profissão, e ao mesmo tempo assegurar a boa conduta moral das estudantes. Mesmo quando a escola freqüentada antes do ingresso no curso era mista, o controle moral era rígido, como afirma a entrevistada a seguir.

Eu estudava no Ginásio Americano, no hoje atual colégio Dois de Julho. Eu estudei lá do quinto ano até 0 terceiro ano científico. Tinha estudantes que não podiam pagar e os que podiam. Aqueles sem condições recebiam bolsas, tinha um internato para pessoas que vinham do interior. Era um colégio misto, mas com muita preocupação (risos). No recreio não podia misturar: era moças de um lado e rapazes do outro. (E 2)

As primeiras turmas da Escola de Enfermagem eram compostas também por professoras primárias que continuaram recebendo seu salário enquanto estudavam, 0 que lhes permitiu a conclusão do curso, pois essas estudantes não possuíam renda suficiente para fazer um curso de formação superior. Esse fato mostra um incentivo governamental para a formação da nova profissão na Bahia, revelando assim a relação intrínseca da formação de enfermeiras com as políticas de saúde ${ }^{13}$.

Eu recebia um dinheiro do estado como professora. 0 tempo que estudei foi contado também como aposentadoria. Uma coisa boa que o Estado fez (...); geralmente as do interior que eram professoras, todas eram comissionadas, quer dizer, nós estudávamos e esse tempo era contado para aposentadoria. E recebíamos o nosso ordenado de professora todo o mês. Aípodíamos nos manter.(E4)

Nas atas consultadas e nos relatos é freqüente a presença da direção da EEUFBA nas atividades do DA e nas decisões do mesmo. Isso reflete o papel de controle da direção, transformando o DA em um instrumento regulador das ações estudantis.

A presidente (D. Haydeé, diretora da Escola) deu por aberta à sessão explicando as finalidades do Diretório Acadêmico da Escola e a maneira de como realizar a eleição da diretoria deste Grêmio. (ATA DO DA, 16.04.1947).
Isto não parecia afetar as estudantes membros do DA. Essa relação política era naturalizada pelas militantes, pois estas não se percebiam como tal.

Eu queria afirmar de novo que essa foi uma época muita suave, serena, da política estudantil. Agora, não deixou de existir as reivindicações que depois foram atendidas. Nós não podíamos reclamar, porque tinha uma professora que nos orientava. Em outros cursos não existia isso e os estudantes podiam reivindicar. (E2)

A tutela mantida pela Escola sobre as estudantes, que além de tudo moravam sob a supervisão da direção escolar, estabelecia uma relação de total subordinação das alunas às professoras, acomodando-as a pensar que nem sequer precisavam reivindicar, pois tudo lhes era dado, e a estabelecer uma relação maternal entre elas.

As principais atividades do DA tinham o propósito de dar prosseguimento às ações da direção da EEUFBA, que objetivavam fortalecer a moral e a base religiosa na formação das enfermeiras e desmistificar o preconceito bastante enraizado na sociedade contra a profissão.

Eu me lembro bem que o plano nosso no Diretório era esse, as alunas ajudarem a mudar o preconceito que existia com a profissão de Enfermagem. Eu trabalhei muito para isso. (E 2)

Quanto à estreita influência da religião na formação e na prática das alunas, inclusive dos membros do DA, isso é reforçado pelo fato de a estrutura física da Escola contar com uma capela, própria para as cerimônias religiosas da Igreja Católica e, além disso, promover aulas de doutrinação religiosa.

A colega presidente com a palavra fez de início um convite geral para uma conferência a ser realizada aqui na Escola no próximo dia dezenove pelo Reverendo Padre Pinheiro; aproveitando lembrou, ainda, as aulas doutrinárias de religião que são realizadas semanalmente, também aqui na Escola, para que haja grande assistência. (ATA DO DA de 12.11.1952)

A recepção às novas estudantes reproduzia uma prática muito comum entre as mulheres das classes sociais mais elevadas, 0 chá. Percebe-se aí a preocupação em legitimar os costumes femininos valorizados pela sociedade, isto é, mostrar as novas estudantes e as suas famílias que a EEUFBA recebia moças com um perfil distinto daquele que remonta à origem da profissão.

Depois de precisa discussão, predominou a idéia de apenas uma simples recepção às novas colegas com chá, doces, trote, etc., festa cuja direção e execução foi entregue as alunas do $2^{\circ}$ ano (classe de 1953) como é rotina da Escola. (ATA DO DA de 22.02.1951) 


\section{CONSIDERAÇÕES FINAIS}

Do exposto, concluímos que a atuação do DA era claramente direcionada pela diretoria da Escola, desde a aprovação da escolha da presidente às ações desenvolvidas, visando legitimar as regras impostas pela direção da Escola e trabalhar na divulgação do próprio curso.

As discussões referentes à Universidade, política local e nacional, quando ocorriam, eram superficiais e aglutinavam pequena quantidade de estudantes, ao contrário do que ocorria em outras unidades da UFBA e no Brasil, onde as lutas gerais dos estudantes giravam em torno da autonomia do País e em defesa do ensino público.

\section{Referências}

1-Haguette TMF. Metodologias qualitativas na sociologia. 4ạed. Petrópolis (R)): Vozes; 1995.

2-Alberti V. Manual de história oral. 3å ed. Rio de Janeiro (RI): FGV; 2005. p. 236.

3-Silva DGV, Trentini M. Narrativas como técnica de pesquisa em enfermagem. Rev Latino-am Enfermagem [on-line]. 2002 jun; [citado 28 jan 2008]; 10(3): 423-32. Disponível em: http://www.scielo.br/ scielo.

4-Fausto B. História do Brasil. 10ミ̨ ed. São Paulo (SP): USP; 2002.

5-Brandão $A C$, Duar te MF. Movimentos culturais de juventude. $2 \stackrel{2}{\text { a ed. }}$ São Paulo (SP): Moderna; 2004.

6-Singer P, Campos O, Oliveira EM. Prevenir e curar: 0 controle social através dos serviços de saúde. Rio de Janeiro(RJ): Forense Universitária; 1978.
Não sem razão isso acontecia. A insignificante participação das alunas de Enfermagem no movimento estudantil e a alienação política destas retratam com fidelidade a situação da mulher na sociedade brasileira. Revelam também que os padrões de formação assumidos nas escolas de Enfermagem no Brasil, sem exceção da EEUFBA, seguindo o padrão militar, com caráter moral rígido e forte religiosidade, só faziam acentuar o distanciamento das jovens militantes de qualquer ação que tivesse conotação política. E que este padrão ainda hoje repercute no movimento estudantil de Enfermagem, com outras roupagens.

7-Lima TGFMS, Baptista SS. Circunstâncias de criação das escolas de enfer magem do estado do Rio de Janeiro. Esc Anna Nery Rev Enferm 2000 ago; 4(2): 197-208.

8-Mendes A. Movimento estudantil no Brasil. São Paulo (SP): Brasiliense; 1981.

9-Poerner Al. 0 poder jovem: história da participação política dos estudantes brasileiros. Rio de Janeiro (RI): Civilização Brasileira; 1968. 10-Nascimento $A B$. Trajetória da juventude brasileira: dos anos 50 ao final do século. Salvador (BA): Secretária da Cultura e Turismo/ EDUFBA; 1999.

11-Fernandes JD, coordenadora. Memorial Escola de Enfermagem 1946-1996. Salvador (BA): UFBA; 2001

12-Passos ES. De anjos a mulheres: ideologias e valores na formação de enfermeiras. Salvador(BA): EDUFBA/EGBA; 1996. p. 209.

13-Germano RM. Educação e ideologia da enfermagem no Brasil. 3 a ed. São Paulo (SP): Cortez; 1993. 